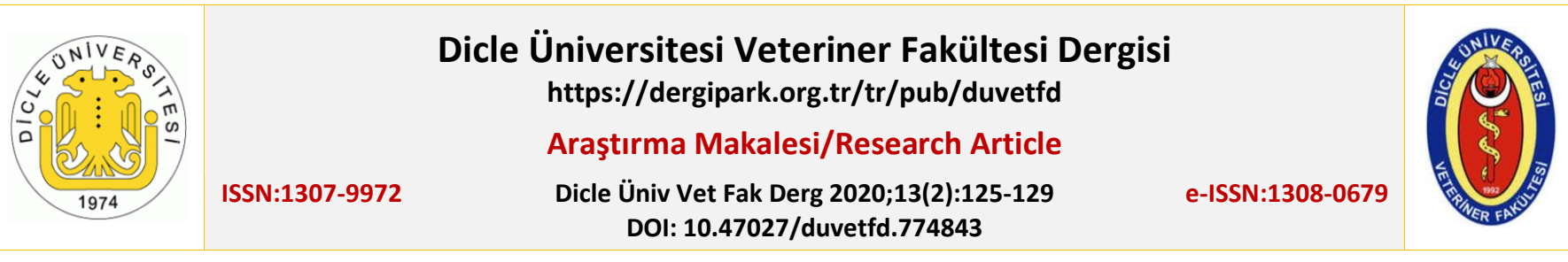

\title{
Yabani Kanatlılarda Salmonella Spp. İzolasyonu ve Serotiplendirilmesi
}

\author{
Mehmet Ali ONBÜYÜK ${ }^{1, a,}$, Oktay KESKIN ${ }^{2, b, \bowtie}$ \\ ${ }^{1}$ Eyyübiye İlçe Tarım ve Orman Müdürlüğü, Eyyübiye/Şanlıurfa, TÜRKiYE \\ ${ }^{2}$ Harran Üniversitesi, Veteriner Fakültesi, Mikrobiyoloji Anabilim Dalı, 63000, Şanlıurfa, TÜRKiYE
}

aORCID: 0000-0003-4549-4772; bORCID: 0000-0002-5977-7872

\begin{tabular}{ccc}
\hline Geliş Tarihi/Received & Kabul Tarihi/Accepted & Yayın Tarihi/Published \\
28.07 .2020 & 19.11 .2020 & 31.12 .2020 \\
\hline
\end{tabular}

Öz

Bu çalışmada yabani olarak yaşayan kanatlı hayvanların dışkılarından Salmonella spp. izolasyonu, identifikasyonu ve serotiplerinin belirlenmesi amaçlanmıştır. Bu amaçla, Ocak 2018 - Mayıs 2019 tarihleri arasında Tarım ve Orman Bakanlığı Şanlıurfa Doğa Koruma ve Milli Parklar Müdürlüğü rehabilitasyon merkezine getirilen yabani kanatılırdan toplam 180 adet dışkı örneği alınmıştır. Bakteriyolojik kültür sonucunda 13 adedi $(\% 81,25)$ Salmonella Typhimurium, 3 adedi $(\% 18,75)$ Salmonella Enteriditis olarak serotiplendirilen toplam 16 adet $(\% 8,9)$ Salmonella izolasyonu yapıldı. Bu izolasyonlar, örnek alınan 8 farklı yabani kanatlı türüne ait dışkılardan gerçekleştirildi ancak 7 yabani kanatlı türünden alınan örneklerden izolasyon yapılamadı. Sonuç olarak doğada yaralı veya hasta olarak bulunarak rehabilitasyon merkezine getirilen yabani kanatılardan alınan dışkı örneklerinden gerek hayvanlarda gerekse insanlarda görülen salmonellozis vakalarından sıkıkla sorumlu olan $S$. Typhimurium ve $S$. Enteriditis serotipleri izole edildi. Bu nedenle yabani kanatılırın evcil kanatlı ve memeli hayvanlar ile insanlara Salmonella etkenlerinin taşınması açısından risk taşıdığı ve bu bağlamda gerekli sanitasyon önlemlerinin alınmasının hayvan ve halk sağlığı için yararlı olabileceği sonucuna varıldı.

Anahtar Kelimeler: Salmonella, serotip, yabani kuş

Isolation, Identification and Serotyping of Salmonella Spp. in Wild Birds

\section{Abstract}

In this study it was aimed to isolate, identify and serotype Salmonella spp. from the feces of wild birds. With this purpose, a total 180 fecal samples were collected from the wild birds brought to rehabilitation center of Agriculture and Forestry Minister, Şanlıurfa Directorate of Nature Protection National Parks between the dates January 2018 - May 2019. A total of 16 (8.9\%) Salmonella spp. isolations that are serotyped were made. At the end of bacterial culture studies, 13 samples $(81,25 \%)$ and 3 samples (18.75\%) were identified as Salmonella Typhimurium and Salmonella Enteriditis, respectively. These isolations were made from 8 different wild bird species but, no isolation could be made from the samples collected from the other seven wild bird species. As conclusion, $S$. Typhimurium and $S$. Enteriditis serotypes which are commonly responsible for human and animal salmonellosis were isolated from the faeces of the sick and wounded wild birds brought to the rehabilitation centers. For this reason, it was concluded that the wild birds carry the risk the transmission of Salmonellosis agents to the domestic birds, mammals and human and to take necessary sanitary measures might help for animal and public health in this regard.

Key Words: Salmonella, serotype, wild bird

\section{Giriş}

Salmonella etkenleri doğada yaygın olarak bulunmakta olup insan ve hayvanlarda enfeksiyonlara neden olabildikleri gibi gıda zehirlenmelerinin ve özel bazı lokal enfeksiyonların sorumlusu olarak da bilinmektedir. Salmonella etkenleri tarafından meydana getirilen enterik enfeksiyonların hayvanlar arasında bulaşma eğiliminin hızlı olması nedeniyle ekonomik önemi fazladır. Bazı Salmonella türleri zoonoz olmasından dolayı insanlara da geçebilmektedir. İnsanlarda süt, kontamine yumurta, et gibi hayvansal kaynaklı gıdalar önemli rol oynamaktadır (1-3). Her yıl Amerika Birleşik Devletleri'nde yaklaşık 76 milyon gıda kaynaklı hastalık, 325.000 hastanede yatan vaka ve 5000 ölüm olayı görülürken, bunlardan 1,4 milyon insan salmonellozis vakası ve yaklaşık olarak 500-600 adet Salmonella 'ya bağlı ölüm olayı görülmektedir $(3,4)$.

Salmonella'lar adlarını Amerikalı bakteriyolog Salmon 'dan almaktadır (5). Salmonella cinsinin ilk sınıflandırması bir serotip-bir tür kavramından köken almış ve herbir serotipin ayrı bir tür olduğu düşünülmüştür (6). "Bergey’s Manual of Determinative Bacteriology"nin 1. Baskısında (1923) Salmonella cinsi biyokimyasal özelliklere göre 17 tür, 1948' de aynı 
kitabın 6. baskısında ise 150 Salmonella serotipi tanımlanmıştır. "Approval Lists of Bacterial Names" 1980 yılında, Salmonella cinsinin 5 tür ve 2000 'den fazla serovardan oluştuğu belirtilmiştir $(7,8)$.

Qunin ve ark. (2), Salmonella'ları 7 alt gurup olarak gruplandırmışlardır. Günümüzde, Salmonella cinsi, Salmonella enterica ve Salmonella bongori olmak üzere iki türe ayrılmaktadır. S. enterica biyokimyasal özellikleri dikkate alınarak S. enterica subspecies enterica (subsp I), S. enterica subsp. salamae (subsp II), S. enterica subsp. arizonae (subsp III), S. enterica subsp. diarizonae (subsp IIIb), S. enterica subsp. houtenae (subsp IV), S. enterica subsp. indica (subspVI) olmak üzere 6 alt guruba ayrılmaktadır $(6,9,10)$. $S$. bongori'nin ise alt türü bulunmamaktadır $(11,12)$. Bu çalışmaların sonucunda uzun süredir adlandırılan Salmonella serovarlarını tür olarak kullanma sistemi artık geçerliliğini yitirmiştir. Daha önce Salmonella typhimurium olarak adlandırılan bir bakteri artık Salmonella enterica subsp. enterica serotype Typhimurium (kısaltılmış olarak da Salmonella ser. Typhimurium veya Salmonella Typhimurium) olarak adlandrılmaktadır $(6,13)$.

Antijenik yönden klasifikasyonu yapılan Salmonella'lar Kauffmann-White şemasında sıralanmıştır. İdentifiye edilen yeni Salmonella serovarları "World Healt Organasition (WHO) Collaborating Centre for Reference and Research on Salmonella" tarafından bu şemaya eklenip güncellenmektedir. Bu yeni serovarlar Pasteur Enstitüsü yayını olan "Research Microbiology" dergisinde genellikle her yıl yayınlanmaktadır (14). 2000, 2001, 2002, 2003 ve 2004 yıllarında yayınlanan makalelerde sırasıyla 14, 12, 22 ve 18 yeni Salmonella serotipi tanımlanmış ve böylece toplam Salmonella serovar sayısı 2541' e ulaşmıştır (15).

Salmonella cinsindeki bakteriler portörlük, lokal apseler ve infeksiyonlar, gastroenterit, septisemi, paratifo, tifo gibi geniş bir infeksiyon spektrumu oluştururlar. Tifo dışında diğer klinik tablolar tür içindeki farklı alt türler ve serovarlar ve çok farklı bakteriler tarafından oluşturulabilir. Dolayısıyla infeksiyonların kesin tanısı etkenlerin izolasyon ve identifikasyonu ile mümkündür (16).

Bu çalışmada yabani olarak yaşayan kanatı hayvanların dışkılarından Salmonella spp. izolasyonu, identifikasyonu ve serotiplerinin belirlenmesi amaçlanmıştır.

\section{MATERYAL VE METOT}

\section{Dışkı Örnekleri}

Salmonella izolasyonu ve identifikasyonu amacıyla; Ocak 2018 - Mayıs 2019 tarihleri arasında Tarım ve Orman Bakanlığına bağlı Şanlurfa Doğa Koruma ve Milli Parklar Müdürlüğü'ne ait Karaköprü ilçesinde bulunan rehabilitasyon merkezine getirilen yabani kanatlılardan toplam 180 adet dışkı örneği alındı. Örnek alınan yabani kanatlı türleri ve örnek sayıları Tablo 1'de gösterilmiştir. Rehabilitasyon merkezinde ayrı bölmelerde tutulan yabani kanatlıların bulunduğu kafeslerden sabah temizliği yapılmadan önce taze dışkı örnekleri steril dışkı kaplarına alınarak soğuk zincirde ve kısa sürede Harran Üniversitesi Veteriner Fakültesi Mikrobiyoloji Anabilim Dalı laboratuvarına ulaştırıldı.
Tablo 1. Dışkı örnek alınan yabani kanatlı türleri ve alınan örnek sayıları

\begin{tabular}{lc} 
Örnek alınan hayvan türü & Örnek sayısı \\
\hline Şahin & 23 \\
Baykuş & 14 \\
Peçeli baykuş & 15 \\
Leykek & 4 \\
Yabani ördek & 9 \\
Kızıl şahin & 20 \\
Atmaca & 7 \\
Kerkenez & 3 \\
Kumru & 2 \\
Kaya güvercini & 42 \\
Puhu kuşu & 7 \\
Alaca baykuş & 5 \\
Yabani kaz & 9 \\
Keklik & 16 \\
Gri balıkçı & 4 \\
Toplam & 180 \\
\hline &
\end{tabular}

\section{İzolasyon}

Bu amaçla Uluslararası Standartlar Örgütü-ISO 6579 (2007) ve Tarım ve Orman Bakanlığı'nın Bakteriyoloji Metot Birliği'nde (17) belirtildiği gibi laboratuvara getirilen dışkı örneklerinden $1 \mathrm{~g}$ dışkı alınarak $9 \mathrm{ml}$ Tamponlanmış Peptonlu Su (TPS) ile homojenize edilerek ön zenginleştirme amacıyla $37^{\circ} \mathrm{C}^{\prime}$ de $18-20$ saat inkübe edildi. Ön zenginleştirme işleminden sonra kültürden 3 damla alınarak Modified Semi-Solid Rappaport-Vassiliadis (MSRV) base mediuma aralarında eşit mesafe bırakarak ekim yapıldı ve $41,5^{\circ} \mathrm{C}^{\prime}$ de 16 saat zenginleştirme için inkübasyona bırakıldı. Süre sonunda besiyerinde mavi renkten beyaza doğru renk değişim alanları oluşan bölgelerin uç noktasından bir öze kültür alınarak Xylose Lysine Deoxycholate (XLD) agara tek koloni düşecek şekilde ekilerek $37^{\circ} \mathrm{C}^{\prime}$ de 24 saat inkübe edildi. XLD'de siyah merkezli kırmızı koloniler şüpheli kabul edilerek saf kültür elde etmek için Nutrient buyyona ekildi. Elde edilen saf kültürün biyokimyasal doğrulamasına geçildi.

\section{Identifikasyon}

\section{Biyokimyasal testler}

Şüpheli kolonilerden elde edilen saf kültürlerden Nutrient Agar (NA)'a ekimler yapılarak elde edilen tek koloni ile oksidaz testi yapıldı ve negatif olan kolonilerin biyokimyasal testleri yapıldı. Bu amaçla klasik biyokimyasal yöntemler kullanılarak laktoz (-), glukoz (+), sukroz (-), gaz (+), $\mathrm{H}_{2} \mathrm{~S}(+)$, üre (-), indol (-), VP (-), lisin dekarboksilaz (+), b-galaktosidaz (-) kültürler Salmonella spp. olarak kabul edildi $(2,17)$.

\section{Serolojik testler}

Biyokimyasal testler sonucunda Salmonella spp. olarak kabul edilen bakteriler Kaufmann-White şemasına göre polyvalan "O" antiserumları (BD DIFCO) ile lam aglütinasyon testine alındı ve daha sonra pozitif bulunan spesifik grup antiserumlarıyla (BD DIFCO) teste tabi tutuldu $(2,17)$. 


\section{Etik Onay}

Çalışma, Harran Üniversitesi Hayvan Deneyleri Yerel Etik Kurulu'nun 13/03/2018-E.11399 tarih ve sayılı kararı ile Orman ve Su İşleri Bakanlığı Doğa Koruma ve Milli Parklar Genel Müdürlüğü'nün 18/01/2018-2036 tarih ve sayılı olurları ile gerçekleştirilmiştir.

\section{BULGULAR}

\section{İzolasyon ve İdentifikasyon Bulguları}

Alınan 180 adet toplam dışkı örneğinden, biyokimyasal testlerle Salmonella olduğu belirlenen 16 adet $(\% 8,9)$ izolat elde edildi. Bu 16 izolatın 13 adedi $(\% 81,25)$ 'nin B serogrubunda olduğu, bu suşun faz 1 antiserumlarından "i", faz 2 antiserumlarından "1,2" ile aglutinasyon verdiği görüldü ve antijenik formulü "1,4,(5),12:i:1,2" olarak belirlendi. Bu nedenle 13 izolat $S$. Typhimurium olarak tiplendirildi. Öte yandan 3 izolat $(\% 18,75)^{\prime}$ ın D1 serogrubunda olduğu, hareketli olan suşların tamamının "faz 1 " antiserumundan "g,m" ile aglutinasyon verdiği belirlendi ve suşların antijenik formulleri " 1 , 9, 12: g,m:-" olarak saptandı. Bu nedenle $S$. Enteritidis olarak tiplendirildi. Çalışmada örnek alınan 8 farklı türe ait dışkılardan Salmonella izolasyonu yapıldı ancak 7 türden alınan örneklerden izolasyon yapılamadı. Çalışmada dışkı alınan yabani kanatlı türüne göre izole edilen serotipler ve izolasyon oranları Tablo 2' de gösterilmiştir.

Tablo 2. Yabani kanatlı türüne göre Salmonella izole edilen serotipler ve izolasyon oranları

\begin{tabular}{lccr}
$\begin{array}{l}\text { Örnek alının hay- } \\
\text { van türü }\end{array}$ & $\begin{array}{c}\text { Örnek } \\
\text { sayısı }\end{array}$ & $\begin{array}{c}\text { İzolasyon sayısı ve } \\
\text { oranı (\%) }\end{array}$ & Serotipi \\
\hline Şahin & 23 & $2(8,6)$ & $\mathrm{T}, \mathrm{E}$, \\
Baykuş & 14 & $1(7,1)$ & $\mathrm{T}$ \\
Peçeli baykuş & 15 & $1(6,6)$ & $\mathrm{T}$ \\
Leykek & 4 & - & \\
Yabani ördek & 9 & $2(22,2)$ & $\mathrm{T}, \mathrm{T}$ \\
Kızıl şahin & 20 & $3(15,0)$ & $\mathrm{E}, \mathrm{T}, \mathrm{T}$ \\
Atmaca & 7 & - & \\
Kerkenez & 3 & - & \\
Kumru & 2 & - & $\mathrm{T}, \mathrm{T}$ \\
Kaya güvercini & 42 & $2(4,7)$ & \\
Puhu kuşu & 7 & - & $\mathrm{T}, \mathrm{T}$ \\
Alaca baykuş & 5 & $2(40)$ & \\
Yabani kaz & 9 & - & T, E, T \\
Keklik & 16 & $3(18,7)$ & \\
Gri balıkçıl & 4 & - & 16 \\
Toplam & 180 & $16(8.9)$ & \\
\hline
\end{tabular}

T: Salmonella Typhimurium, E: Salmonella Enteriditis

\section{TARTIŞMA VE SONUÇ}

Doğada yaygın olarak bulunan Salmonella etkenleri insan ve hayvanlarda gerek neden oldukları enfeksiyonlar gerekse gıda zehirlenmeleri ve özel bazı lokal enfeksiyonlar nedeniyle önem taşırlar. Hayvanlarda Salmonella etkenlerinin oluşturduğu enterik enfeksiyonların hayvanlar arasında bulaşma eğiliminin hızlı olması nedeniyle ekonomik önemi fazladır. Ayrıca bazı Salmonella etkenlerinin zoonotik özelliğinden dolayı da halk sağlığı açısından önemli bir risk oluşturmaktadırlar.

Khidhir ve Aref (18) yabani yaşam süren 3 kuş türüne ait 136 örnekten \%1,4, Andres ve ark. (19), yüksek salmonellozis prevalansı görülen domuz çiftliklerinin bulunduğu bölgelerden yakalanan yabani kuşlardan aldıkları 810 dışkı örneğinden ortalama $\% 1,85$, bölgelere göre ise $\% 1-4,4$, Konicek ve ark. (20) Avusturya-Çek Cumhuriyeti sınır bölgesinde 81 farklı türde yer alan 1325 yabani kuştan 1191 kloakal svap örneğinden \%2,2, Matias ve ark (21), yabani kuşlardan topladığı 109 numunede \%2,75, Rahmani ve ark. (22), 24 farklı türde yer alan yabani kuşlardan alınmış 668 numuneden $\% 2,8$, Mirzaie ve ark. (23), 470 serçeden \%3,8, Azikuru ve Sischo (24), yabani kuşların dışkılarından $\% 4,3$, Vico ve Mainar-Jaime (25)' 34 yabani kuş dışkısından \%5,1, Kobayashi ve ark. (26) 55 farklı yabani kuştan toplanan 328 dışkı örneğinden \%5,8, Al-Aalim (27) 75 yabani güvercin dışkı örneğinden $\% 8$, Millan ve ark. (28) yabani kanatlılardan topladıkları 205 numuneden $\% 8,5$, Awadallah ve ve ark. (29) yabani kanatlılardan aldıkları 400 kloakal svap örneğinden $\% 10,75$, Hidasi ve ark.(30) yabani güvercinlerden aldıkları 200 örnekten $\% 13$, Shalaby ve ark. (31) yabani kanatlı türünden topladığı 298 örnekten \%13,5, Staji ve Zandiar (32) hayvanat bahçesi ve evcil hayvan satış noktalarından aldıkları 115 kuş örneğinden \%23,4 Salmonella izolasyon oranı rapor etmişlerdir. Bu çalışmada da elde edilen \%8,9 izolasyon oranı araştırıcılar tarafından bildirilen oranlara yakın bulundu. Ancak bazı araştırıcıların bildirdikleri daha düşük veya yüksek oranların incelenen numune sayısı, numune toplanan mevsim, numune alınan kuş türü, hayvanların hayvanat bahçesi ve satış noktalarında toplu barındırılmaları gibi faktörlere bağlı olabileceği düşünülmektedir.

Matias ve ark. (21) ise Salmonella izolasyonu yapılan 3 örnekten 1'ini S. Typhimurium olarak rapor etmişlerdir. Shably ve ark. (31) ise izole ettikleri Salmonella etkenlerinin serotiplendirmesinde en çok görülen serotipin \%40,63 oranla S. Typhimurium olduğunu bildirmişlerdir. Al-Aalim (27), yabani güvercinlerden izole ettiği toplam 6 Salmonella izolatının 3'ünün $S$. Typhimurium olduğunu bildirmiştir. Andres ve ark. (19), S. Typhimurium serotipinin izolasyon oranı \%69,23 olarak en yaygın serotip olduğunu bildirmişlerdir. Vico ve Mainar-Jaime (25) yabani kanatlılardan izole ettikleri Salmonella etkenlerinin \%75'ini S. Typhimurium olarak serotiplendirmişlerdir. Hughes ver ark. (33), yabani kanatlılardan izole ettikleri 32 Salmonella izolatının 29'unu S. Typhimurium olarak bulmuşlardır. Kobayashi ve ark. (26) 328 kloakal örnekten tamamı S. Typhimurium olarak serotiplendirilen 19 izolasyon yapmışlardır. Kraeiec ve ark. (34) ölü olarak getirilen 6 adet kuştan S. Typhimurium izole etmişlerdir. Khidir ve Aref (18) toplam 136 yabani kanatlı örneğinden 2 adet izolasyon yapmıştır ve her ikisi de S. Typhimurium olarak identifiye edilmiştir. Bu çalışmada da izole edilen Salmonella etkenlerinin \%81,25'i S. Typhimurium olarak belirlendi. Bu çalışmada elde edilen veriler de birçok araştırıcının S. Typhimurium' un en yaygın serotip olduğunu belirten bildirimleri ile uyumlu bulundu. 
Obukhovska (35) yabani kanatlılarda yapmış olduğu çaIışmada Salmonella izolatlarının \%53,2'sini S. Enteriditis olarak identifiye etmiştir. Konicek ve ark. (20) kazlardan izole ettiği 2 serotipten 1'ini S. Enteriditis olarak bildirmiştir. Staji ve ark. (32) yaptıkları çalışmada izole ettikleri 32 izolatın 19'unu S. Enteriditis ve $13^{\prime}$ ünü $S$. Typhimurium olarak serotiplendirmiştir. Hidasi ve ark. (30) yabani güvercinlerden izole ettikileri 26 Salmonella izolatlarının 19'unu Salmonella Schwazengrund, 6'sını S. Typhimurium ve 1 'ini S. Enteriditis olarak belirlemişlerdir. Millan ve ark. (28), 3 kartaldan 1 ve 5 atmacadan 1 olmak üzere 2 adet $S$. Typhimurium, 1 alaca baykuştan da $1 \mathrm{~S}$. Enteriditis izole ettiklerini bildirmişlerdir.

Awadallah ve ark. (29) yabani kanatlılardan izole ettikleri 6 Salmonella izolatının 2'sini S. Enteriditis, 1'ini de S. Typhimurium olarak identifiye etmişlerdir. Rahmani ve ark. (22), kanarya, güvercin, psittasin ve kartallardan izole ettikleri suşların 9'unun $B, 6$ 'sının $C$ ve $4^{\prime}$ ünün de $D$ serogrubunda yer aldığını bildirmişlerdir. Mirzaie ve ark. (23), 470 serçeden izole ettikleri 18 izolatın 9'unu S. Typhimurium, 8'ini S. Enteriditis ve 1'ini de Salmonella Montevideo olarak bildirmişlerdir. Bu çalışmada da izole edilen 16 suşun 13 adedi $(\% 81,25)$ S. Typhimurium, 3 adedi $(\% 18,75)$ S. Enteriditis olarak tiplendirilmiş olup, elde edilen bu bulguların araştırıcıların bildirimleriyle uyumlu olduğu belirlendi.

Sonuç olarak;

1. Doğada yaralı veya hasta olarak bulunarak Tarım ve Orman Bakanlığına bağı Doğa Koruma ve Milli Parklar Genel Müdürlüğü Şanlıurfa Şubesi'ne ait Karaköprü ilçesinde bulunan rehabilitasyon merkezine getirilen yabani kanatlılardan alınan dışkı örneklerinden S. Typhimurium ve S. Enteriditis izole edilmiş olup bu serotipler gerek hayvanlarda, gerekse insanlarda görülen salmonellozis vakalarından sıklıkla sorumlu olan serotiplerdir. Bu nedenle yabani kanatlıların evcil kanatlı, memeli hayvanlar ve insanlara Salmonella etkenlerinin taşınması açısından risk taşıdığı kanısına varıldı.

2. Salmonella etkenlerinin yabani kanatlılarda izlenmesinin gerek hayvan sağlığı ve gerekse halk sağlığı açısından önem taşıdığı düşünülmektedir. Bu nedenle özellikle de salmonellozis vakalarının görüldüğü bölgelerde yabani kanatlılardaki Salmonella taşıyıcılığının belirlenmesi infeksiyonun kontrolü açısından önemli katkı sağlayacaktır.

3. Çalışmanın yürütüldüğü rehabilitasyon merkezleri, hayvanat bahçeleri, belediyelere ait veya özel yabani kanatIıların barındırıldığı alanlar gibi bölgelerde çalışan ve çevresindeki insanların sağlığı açısından kuşlara bakan veya besleyen kişilerin hijyen konusunda eğitilmelerinin de yararlı olacağı düşünüldü.

\section{KAYNAKLAR}

1. Koneman EW, Allen SD, Janda WM, Schreckenberger PC, Winn WC. (1992). Diagnostic Microbiology. Fourth Edition, JB. Lippincot Company, Philadelphia.

2. Quinn PJ, Carter ME, Markey BK, Carter GR. (1994). Mosby-Year Book Europe Limited. pp.209-236. Lynton House, London WC1H9LB, England.

3. Anonim. Salmonellosis Institute for International Cooperation in Animal Biologics. 2005.
Erişim:https://salmonella360.com/content/files/317/Leaflet_EN_OIE_2005_Salmonellosis. Erişim Tarihi: 05.08.2019.

4. Mead PS, Slutsker L, Dietz V, et al. (1999). Food Related Illness and Death in the United States. Emerg Infect Dis. 5: 607-625.

5. İzgür M. (2006). Salmonella İnfeksiyonları. (İçinde): Veteriner Mikrobiyoloji (Bakteriyel Hastalıklar). Aydın N, Paracıkoğlu J. (editörler). s.116-121. Illk-Emek Matbaacılık ve Yayıncılık, Ankara, Türkiye.

6. Brenner FW, Villar RG, Angulo FJ, Tauxe R, Swaminathan B. (2000). Salmonella nomenclature. J Clin Microbiol. 38: 24652467.

7. Ezaki T, Kawamura Y, Yabuuchi E. (2000). Recognition of Nomenclatural Standing of Salmonella typhi (Approved Lists 1980), Salmonella enteritidis (Approved Lists 1980) and Salmonella typhimurium (Approved Lists 1980), and Conservation of the Specific Epithets Enteritidis and Typhimurium, Request for an Opinion. Int J Syst Evol Microbiol. 50(2) : 945-947.

8. Le Minor L, Veron M, Popoff MY. (1985). Salmonella choleraesuis subsp. arizonae comb. nov. etc. In Validation of the Publication of New Names and New Combinations Previously Effectively Published Outside the IJSB, List no. 18. Int J Syst Bacteriol. 35: 375-376.

9. Le Minor L, Popoff MY. (1987). Designation of Salmonella enterica sp. Nov., nom. Rev. As the Type and Only Species of the Genus Salmonella. Int J Syst Bacteriol. 37: 465-468.

10. Holt JG, Krieg NR, Sneath PHA, Staley JT, Williams ST. (1994). Bergey's Manuel of Determinative Bacteriology Chapter. William RH,Williams and Wilkins (eds). 5th ed. pp.186-187. Maryland, USA

11. Reeves MV, Evins GM, Heiba AA, Plikaytis BD, Farmerii JJ. (1989). Clonal Nature of Salmonella typhi and Its Genetic Relatedness to other Salmonella as Shown by Multilocus Enyzme Electrophoresis and Proposal of Salmonella bongori comb. Nov. J Clin Microbiol. 27: 313-320.

12. Popoff MY, Bockemuhl J, Brenner FW. Gheesling LL. (2001). Supplement 2000 (no.44) to the Kauffman-White scheme. Res Microbiol. 152: 907-909.

13. Anonim. (2004). Salmonella Standart ve ileri Tanı. ISBN. 52(0-2): 975-984.

14. Popoff MY, Bockemuhl J, Brenner FW. (2000). Supplement 1998 (no.42) to the Kauffman-White Scheme. Res Microbiol. 151: 6365.

15. Popoff MY, Bockemuhl J, Gheesling LL. (2004). Supplement 2002 (no.46) to the Kauffman-White Scheme. Res Microbiol. 155: 568-570.

16. Bisping W, Amtsberg G. (1988). Farbatlas Zur Diagnose Bacterieller Infectionserreger Der Tiere. Paul Parey Scientific Publishers. pp.171-182. Berlin and Hamburg.

17.Teşhiste Metot Birliği. (2018). Erişim:https://www.tarimorman.gov.tr/GKGM/Belgeler/Veteriner\%20Hizmetleri/teshiste_metod_birligi/bakteriyoloji.pdf. Erişim tarihi: 12.12 . 2018.

18. Khidhir ZK. (2010). Isolation of Salmonella from some Species of Wild Birds in Sulaimania. MJS. 21(4): 49-52.

19. Andrés S, Vico JP, Garrido V, et al. (2013). Epidemiology of Subclinical Salmonellosis in Wild Birds from an Area of High Prevalence of Pig Salmonellosis: Phenotypic and Genetic Profiles of Salmonella Isolates. Zoonoses Public Health. 60(5): 355-365.

20. Konicek C, Vodrážka P, Barták P, et al. (2016). Detection of Zoonotic Pathogens in Wild Birds in the Cross-Border Region Austria-Czech Republic. JWD. 52(4): 850-861. 
21. Matias CAR, Ingrid AP, Maiarados SA, et. al. (2016). Characteristics of Salmonella spp. Isolated from Wild Birds Confiscated in Illegal Trade Markets, Rio de Janeiro, Brazil. BioMed Research International. Article ID 3416864, pp.1-7.

22. Peighambari SM, Yazdani A, Hojjati P. (2011). Salmonella Infection in Birds Kept in Parks and Pet Shops in Tehran, Iran. IJVM. 5(3): 145-148.

23. Mirzaie S, Hassanzadeh M, Ashrafi I. (2010). Identification and Characterization of Salmonella Isolates from Captured House Sparrows. Turk J Vet Anim Sci. 34(2): 181-186.

24. Afema JA, Sischo WM. (2016). Salmonella in Wild Birds Utilizing Protected and Human Impacted Habitats. EcoHealth. 13(3): 558-569.

25. Vico JP, Mainar-Jaime RC. (2011). Salmonellosis in Wild Birds and Its Relationship with the Infection in Finishing Pigs. 9th International Conference on the Epidemiology and Control of Foodborne Pathogens and Antimicrobial Resistance in Pigs and Pork, pp.264-267, June 19-22, Maastricht, The Netherlands.

26. Kobayashi H, Kanazaki M, Shimizu Y, et al. (2007). Salmonella Isolates from Cloacal Swabs and Footpads of Wild Birds in the Immediate Environment of Tokyo Bay. J Vet Med Sci. 69(3): 309-11.

27. Al-Aalim AM. (2017). Isolation and Identificatıon of Salmonella Microorganisms from Pigeons and Their Pathogenicity in Broiler Chicks. Bas J Vet Res. 16(1):333-347.

28. Millán J, Aduriz G, Moreno B, Juste RA, Barral M. (2004). Salmonella Isolates from Wild Birds and Mammals in the Basque Country (Spain). Rev Sci Tech Off Int. Epiz. 23(3): 905-911.

29. Awadallah MA, Merwad AM, Rehab EM. (2013). Prevalence of Zoonotic Escherichia coli and Salmonellae in Wild Birds and $\mathrm{Hu}-$ mans in Egypt with Emphasis on RAPD-PCR Fingerprinting of $E$. Coli. Glob Vet. 11(6): 781-788.
30. Hidasi HW, Andrade MA, Linhares GFC, et al. (2015). Detection of Salmonella enterica in Synanthropic Birds in the Metropolitan Area of Goiania-Go. Clin Microbiol. 4(3):1-6.

31. Shalaby AG, El-Enbaawy MI, Erfan AM, Nasef SA. (2012). Studies on Salmonella Species from Migratory and Native Wild Birds. 1st Conf of An Health Res Inst Assoc. pp. 539-550.

32. Staji H, Zandiar L. (2017). Importance of Wild Species Kept in Captivity as Reservoirs of Salmonella Serotypes for Human in Petting Exhibitions and Zoo in Iran with Focus on Antimicrobial Resistance. Mac Vet Rev. 40 (2): 167-175.

33. Hughes LA, Shopland S, Wigley P, et al. (2008). Characterisation of Salmonella enterica serotype Typhimurium Isolates from Wild Birds in Northern England from 2005 - 2006. BMC Vet Res. 4(4): 1-10.

34. Krawiec M, Pietkiewicz M, Wieliczko A. (2014). Salmonella spp. as a Cause of Mortality and Clinical Symptoms in Free-Living Gardenbird Species in Poland. Pol J Vet Sci. 17(4): 729-731.

35. Obukhovska O. (2013). The Natural Reservoirs of Salmonella Enteritidis in Populations of Wild Birds. Online J Public Health Inform. 5(1): 171.

\section{Sorumlu Yazar:}

\section{Oktay KESKIN}

Harran Üniversitesi, Veteriner Fakültesi, Mikrobiyoloji Ana-

bilim Dalı, 63000, Şanlıurfa, TÜRKIYE

E-mail: okeskin@harran.edu.tr 